Jurnal Keperawatan Silampari

Volume 4, Nomor 1, Desember 2020

e-ISSN: 2581-1975

p-ISSN: 2597-7482

DOI: https://doi.org/10.31539/jks.v4i1.1221

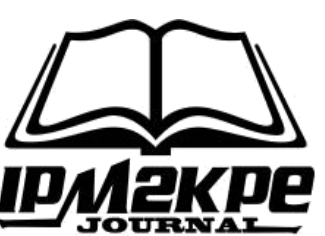

\title{
KEBUTUHAN SPIRITUAL PADA PASIEN DENGAN KANKER STADIUM AKHIR
}

\author{
Maria Komariah $^{1}$, Dessy Adriani ${ }^{2}$, Desy Indrayani ${ }^{3}$, Nina Gartika $^{4}$ \\ Universitas Padjadjaran Bandung ${ }^{1,3}$ \\ Rumah Sakit Hasan Sadikin Bandung ${ }^{2}$ \\ Sekolah Tinggi Ilmu Kesehatan 'Aisyiyah Bandung ${ }^{4}$ \\ maria.komariah@gmail.com ${ }^{1}$
}

\begin{abstract}
ABSTRAK
Tujuan penelitian ini adalah untuk mengkaji kebutuhan spiritual dengan mendapatkan gambaran tentang tingkat kepentingan kebutuhan spiritual berdasarkan 7 dimensi yang dikembangkan oleh Galek. Metode penelitian ini menggunakan metode penelitian deskriptif. Hasil penelitian pada dimensi ketuhanan $(3,63)$, moralitas dan etika $(3,43)$, cinta/rasa memiliki $(3,42)$, berpikiran positif/ rasa syukur/ harapan $(3,40)$, makna dan tujuan (3,39), resolusi/kematian $(3,26)$ dan pada dimensi apresiasi keindahan $(2,98)$. Simpulan, pada pasien kanker stadium lanjut, kebutuhan spiritual tertinggi pada dimensi ketuhanan dan terendah pada dimensi apresiasi keindahan.
\end{abstract}

Kata Kunci : Kajian, Kanker Stadium Lanjut, Kebutuhan, Pasien, Spiritual

\section{ABSTRACT}

This research aims to examine spiritual needs by getting an idea of the level of importance of spiritual needs based on the seven dimensions developed by Galek. This research method uses descriptive research methods. The results of research on the aspects of divinity (3.63), morality and ethics (3.43), love/sense of belonging (3.42), positive thinking/gratitude/hope (3.40), meaning and purpose (3.39) ), resolution/death (3.26) and on the appreciation dimension of beauty (2.98). In conclusion, in advanced cancer patients, the highest spiritual need is in the divine aspect, and the lowest is in the dimension of appreciation of beauty.

Keywords: Study, Advanced Stage Cancer, Needs, Patients, Spiritual

\section{PENDAHULUAN}

Saat ini, penelitian tentang spiritualitas telah meningkat secara kualitas maupun kuantitas dalam dua dekade terakhir pada beberapa professional kesehatan (Komariah, Ibrahim, 2019). Spiritualitas dianggap sebagai dimensi mendasar dari kesehatan pasien karena dapat meningkatkan perasaan tenang dan damai, terutama pada kondisi seseorang sedang mengalami krisis atau ketika didiagnosis penyakit yang mengancam jiwa atau penyakit keganasan (Martins, Caldeira, 2018; Martins et al., 2019). 
Banyak pasien yang dirawat di rumah sakit memerlukan pemenuhan kebutuhan spiritual ini, dan ada kalanya mereka menggunakan sumber daya yang ada pada mereka sendiri, keluarga dan orang yang dianggap ahli agama baik itu dari rumah sakit (rohis) atau dari komunitas mereka tinggal sekedar untuk mendukung dan memenuhi kebutuhan spiritualitas mereka (Caldeira et al., 2017). Oleh karena itu, diperlukan adanya peningkatan kesadaran bahwa perawat dan juga petugas layanan kesehatan lainnya harus mampu mengidentifikasi, mendiagnosis dan mendukung kebutuhan spiritual pasien sebagai komponen pemberian perawatan kesehatan holistic (Caldeira et al., 2017). Pengalaman terkena penyakit kanker sangat berdampak pada kondisi spiritualitas seseorang (Komariah, Ibrahim, 2019).

Aspek dominan pembentukan kualitas hidup penderita kanker adalah aspek psikologis, meliputi spiritualitas, dukungan sosial dan kesejahteraan. Faktanya, aspek psikologis sangat menentukan kualitas hidup, penderita mendapatkan kekuatan dan merasa lebih sehat tanpa obat, hal ini disebabkan karena sugesti dalam diri individu tersebut untuk tetap sehat. Kecerdasan spiritualitas menuntun penderita memiliki penerimaan diri terhadap penyakitnya. Penderita mengalami peningkatan spiritual dibanding sebelum menderita kanker. Penderita merasa lebih dekat dengan Tuhan dan tidak menyalahkan Tuhan, melainkan menganggap sebagai sebuah anugerah Tuhan. Rasa cinta dan nyaman dari dukungan sosial memberi motivasi untuk sembuh dan kuat menjalani hidup. Akhirnya memberikan kesejahteraan yang menentukan kualitas hidup penderita (Anita, 2016).

Penelitian yang dilakukan Endiyono, Herdiana, (2016) menyatakan bahwa terdapat hubungan yang signifikan antara dukungan Spiritual dengan kualitas hidup pasien kanker payudara dengan $p$ value $=0.028$. Saarelainen (2020) mengemukakan pendapat bahwa pada pasien kanker, selain menjadikan mereka siap untuk membantu orang lain meningkatkan makna dan harapan dalam hidup, mereka juga mampu memberi harapan kepada orang lain. Juga, mereka menyimpulkan bahwa lebih dari 93\% pasien kanker percaya bahwa spiritualitas membantu mereka untuk memperkuat harapan mereka

Selanjutnya Anita juga menyatakan bahwa perawatan paliatif berupaya meringankan penderitaan penderita yang sudah sakit parah dan tidak dapat disembuhkan seperti misalnya kanker stadium akhir, penderita penyakit motor neuron, penyakit degeneratif saraf dan penderita HIV/AIDS. Pada akhirnya penderita diharapkan dapat menjalani harihari sakitnya dengan semangat dan tidak putus asa serta memberi dukungan agar mampu melakukan hal-hal yang masih bisa dilakukan dan bermanfaat bagi spiritual penderita. Perawatan paliatif lebih berfokus pada dukungan dan motivasi ke penderita. Kemudian setiap keluhan yang timbul ditangani dengan pemberian obat untuk mengurangi rasa sakit. Perawatan paliatif ini bisa mengeksplorasi individu penderita dan keluarganya bagaimana memberikan perhatian khusus terhadap penderita, penanggulangannya serta kesiapan untuk menghadapi kematian (Anita, 2016).

Oleh karena itu diperlukan suatu kajian tentang kebutuhan spiritual pada pasien. Kajian kebutuhan adalah alat untuk perencanaan program sebagai evaluasi terhadap kapasitas pelayanan perawatan agar sesuai dengan yang dibutuhan pasien (WHO, 2018). Kajian kebutuhan pasien sangat penting bagi rumah sakit dan pengaturan perawatan paliatif, yang berfokus pada kualitas hidup, pengendalian sakit, dan kehidupan sosial 
seseorang, emosional, dan kebutuhan spiritual. Kebutuhan spiritual pasien perlu ditangani apabila perawat ingin memberikan pelayanan holistic yang optimal.

Sehingga peneliti merasa penting untuk memperoleh sebuah pemahaman yang baik dari jenis kebutuhan spiritual pada pasien kanker stadium lanjut di Indonesia. Kemungkinan hasil penelitian kebutuhan spiritual pada kanker akan berbeda sehubungan dengan adanya perbedaan budaya dan agama, sehingga penelitian tersebut tidak bisa diaplikasikan pada kultur dan keyakinan yang lain, termasuk pada budaya Islam di Indonesia.

Penelitian sebelumnya hanya berfokus pada beberapa aspek spiritual saja seperti ketuhanan, berpikir positif serta moral dan etika. Namun penelitian ini menambahkan aspek makna dan tujuan, resolusi/kematian dan pada dimensi apresiasi keindahan.

\section{METODE PENELITIAN \\ Rancangan penelitian}

Rancangan penelitian yang digunakan adalah deskriptif. Instrumen yang digunakan dalam penelitian ini adalah Spiritual Need Survey.

\section{Variabel Penelitian}

Dalam penelitian ini yang akan menjadi variabel adalah kebutuhan spiritual dan subvariabel adalah 7 dimensi kebutuhan spiritual, yaitu Cinta/ rasa memiliki/ menghoramati; Ketuhanan; Berpikir positif/ rasa bersyukur/ harapan/ rasa damai; Makna dan tujuan; Moralitas dan etika; Apresiasi terhadap keindahan; dan Resolusi/ kematian.

\section{Populasi dan Sampel}

Populasi pada penelitian ini adalah seluruh pasien kanker yang didiagnosa telah mengalami stadium lanjut berdasarkan catatan medis. Sedangkan sampel dipilih berdasarkan kriteria: kanker stadium III, mampu berkomunikasi dengan baik, tidak ada gangguan kejiwaan, mampu menulis dan membaca, serta bersedia mengisi kuesioner.

\section{Tahapan Penelitian}

Peneliti mengumpulkan data dengan cara menyebarkan instrumen penelitian berupa spiritual need survey kepada responden yakni pasien kanker stadium lanjut yang di rawat di salah satu rumah sakit di Bandung, berjumlah 40 orang.

\section{Analisis Data}

Data yang sudah sesuai dengan sub-variabel indikator dikelompokkan ke dalam kategori Sangat penting (SP), Penting(P), Cukup penting (CP), kurang penting (KP) Tidak Penting dikode dengan nilai: $4=$ sangat penting, $3=$ penting, $2=$ cukup penting, $1=$ kurang penting, $0=$ tidak penting.

Selanjutnya data tersebut ditabulasikan dengan menghitung nilai rata-rata tingkat kepentingan sesuai kategori pada setiap dimensi kebutuhan spirtual. Analisis nilai rata-rata ini bertujuan untuk mendapatkan gambaran tingkat kebutuhan yang mengidentifikasi domain pada tiap dimensi kebutuhan spiritual. 


\section{HASIL PENELITIAN}

Tabel. 1

Distribusi Frekuensi

Karakteristik Responden

\begin{tabular}{ccc}
\hline Karakteristik & Frekuensi (n) & Presentase (\%) \\
\hline Usia & 15 & 37,5 \\
Dewasa Pertengahan & & 62,5 \\
(26-38 th) & 35 & \\
Dewasa Akhir & & 57,5 \\
(39-65 th) & & 42,5 \\
\hline Pekerjaan & 13 & \\
Bekerja & 17 & 80,0 \\
Tidak bekerja (IRT) & & 20,0 \\
\hline Suku & 32 &
\end{tabular}

Sumber: Data Primer (2018)

Berdasarkan tabel 1 rentang usia responden adalah 27 sampai 64 tahun dengan mayoritas berumur dewasa akhir (39-64 th) yaitu 62.5\%. Suku yang paling banyak ditemukan pada responden adalah suku sunda (80\%). Pekerjaan responden dibedakan menjadi dua kategori, yakni bekerja dan tidak bekerja (ibu rumah tangga).

Tabel. 2

Prevalensi Kebutuhan Spiritual pada Pasien Kanker Stadium Lanjut

\begin{tabular}{ccccc}
\hline Dimensi & $\begin{array}{c}\text { Prevalensi } \\
\text { Butuh }\end{array}$ & $\%$ & $\begin{array}{c}\text { Prevalensi } \\
\text { Tidak Butuh }\end{array}$ & $\%$ \\
\hline Cinta/rasa memiliki/menghormati & 40 & 100 & - & - \\
Ketuhanan & 40 & 100 & - & - \\
Berfikir positif/rasa & 40 & 100 & - & - \\
syukur/harapan/rasa damai & & & - & - \\
Makna dan tujuan & 40 & 100 & - & - \\
Moralitas dan etika & 40 & 100 & - & - \\
Apresiasi keindahan & 40 & 100 & - & - \\
Resolusi/kematian & 40 & 100 & & - \\
\hline
\end{tabular}

Sumber: Data Primer (2018)

Berdasarkan tabel 2 menunjukkan bahwa prevalensi kebutuhan pasien terhadap 7 (tujuh) dimensi spiritual, dan dapat dilihat bahwa seluruh responden (100\%) menyatakan bahwa mereka membutuhkan semua dimensi spiritual tersebut. Penilaian dilakukan terhadap setiap kategori tingkat kebutuhan pasien pada berbagai dimensi kebutuhan spiritual, maka akan didapatkan nilai rata-rata tingkat kebutuhan responden terhadap setiap dimensi spiritual, seperti berikut ini: 
Tabel. 3

Rata-Rata Tingkat Kebutuhan pada Berbagai Dimensi Spiritual

\begin{tabular}{cc}
\hline Dimensi & Tingkat \\
Kebutuhan Spiritual & Kebutuhan \\
\hline Cinta/rasa memiliki/menghormati & 3.42 \\
Ketuhanan & 3.63 \\
Berfikir positif/rasa & 3.40 \\
syukur/harapan/rasa damai & 3.39 \\
Makna dan tujuan & 3.43 \\
Moralitas dan etika & 2.98 \\
Apresiasi keindahan & 3.26 \\
Resolusi/kematian &
\end{tabular}

Sumber: Data Primer (2018)

Berdasarkan tabel 3 tersebut terlihat bahwa dimensi ketuhanan menempati urutan pertama tingkat kebutuhan dengan nilai rata-rata paling tinggi (3.63). Hal ini menunjukkan bahwa dimensi Ketuhanan adalah dimensi spiritual yang paling dibutuhkan oleh responden.

\section{PEMBAHASAN}

\section{Dimensi Ketuhanan}

Pada dimensi ini hampir seluruh pasien mengatakan menjalankan ibadah adalah kebutuhan sangat penting tapi karena dimensi ini mencakup bukan saja ritual peribadatan tetapi juga mengikuti layanan spiritual, membaca Kitab Suci atau buku-buku tentang Agama, percaya akan adanya sesuatu kekuatan diluar tubuh manusia, dan memiliki seseorang yang selalu mendoakan. Kebutuhan ini merupakan kebutuhan yang sangat penting yang dirasakan pasien dan menjadi urutan pertama/tertinggi dengan nilai rata-rata tingkat kebutuhan (3.63).

Penelitian yang dilakukan Puspita pada tahun 2019 menunjukkan bahwa perkembangan dapat menentukan proses pemenuhan kebutuhan spiritual, karena setiap tahap perkembangan memiliki cara meyakini kepercayaan terhadap tuhan. Di mana dalam usia produktif ini lebih matang dalam pengetahuannya mengenai agama, sehingga lebih mudah untuk diberikan arahan mengenai spiritualnya (Puspita, Mahmudah, 2019).

Penelitian yang dilakukan Endiyono, Herdiana, (2016) menyatakan bahwa terdapat hubungan yang signifikan antara dukungan Spiritual dengan kualitas hidup pasien kanker payudara dengan $p$ value $=0.028$. Dengan adanya dukungan spiritual yang timbul dari diri sendiri maupun yang berasal dari orang-orang disekitar akan menjadikanya berfikiran positif, keyakinan akan kekuasaan Tuhan tersebut menjadikan pasien pasrah, ikhlas dan menerima takdir yang diberikan oleh Tuhan.

Sehingga, dapat disimpulkan bahwa, aspek agama memiliki peran yang kuat, sama halnya dengan kondisi di Indonesia, yang mayoritas beragama Islam dan religious (Widiasih, Nelson, 2018). Dalam masyarakat Islam, ritual keagamaan seperti salat dan permohonan do'a memainkan peranan penting dalam menerima penyakit (Sajadi et al., 2018). Berdo'a memiliki peran penting dalam mengatasi kanker dan membantu pasien untuk meningkatkan kesehatan spiritual ketika mereka sedang sakit (Sastra, 2020). 


\section{Dimensi Moralitas dan Etika}

Budaya Indonesia secara universal termasuk dalam budaya timur. Budaya timur memiliki tenggang rasa yang kuat, ramah dan rukun terhadap sesama, dan menjunjung tinggi etika dan nilai-nilai moral/kemanusiaan (Arifin, Lestari, 2019). Sedangkan Budaya Sunda termasuk budaya spesifik yang sangat menjunjung tinggi sopan santun. Cermin budaya dan kultur masyarakat sunda terkenal dengan istilah someah yang artinya ramah tamah, lemah lembut, murah senyum. Budaya Sunda sangat menghormati orang tua dan menyayangi pada yang lebih muda sesuai dengan prinsip hidupnya yaitu silih asah, silih asih, silih asuh (Mulyani Ratnapuri, 2018). Contoh pada penggunaan bahasa daerah, diajarkan bagaimana berbicara yang halus pada orang lebih tua. Selain itu karakter/pola hidup budaya yang terdiri dari 5 unsur yaitu cageur, bageur, bener, singer, dan pinter.

\section{Dimensi Cinta/Rasa Memiliki/Menghormati}

Kebutuhan pasien terhadap dimensi ini sudah hampir sebagian besar terpenuhi. Tingginya faktor dukungan keluarga membuat kebutuhan Cinta/rasa memiliki/ menghormati menjadi kebutuhan yang penting bagi responden. Hal ini disebabkan karena keluarga pasien dan tenaga kesehatan merupakan faktor yang berpotensi untuk pemenuhan kebutuhan spiritual pasien. Pasien yang tidak memiliki dukungan sosial dari lingkungan sekitar lebih cenderung melapor ketidakadekuatan pemenuhan kebutuhan (Saarelainen, 2020).

Pada saat peneliti melakukan wawancara dengan responden. Hampir seluruh responden ditemani oleh keluarga dan keluarga mengatakan akan selalu menemani, memberi dukungan pada program pengobatan, serta mencurahkan kasih sayang pada pasien dalam kondisi apapun juga. Hal ini jika dilihat dari karakteristik responden yang $80 \%$ berasal dari suku Sunda maka hal yang sangat wajar bila seluruh pasien didampingi keluarga karena mereka mempunyai pedoman hidup silih asah, silih asih, dan silih asuh.

\section{Dimensi Berpikir Positif/Rasa Syukur/ Harapan/ Rasa Damai}

Saarelainen (2020) mengemukakan pendapat bahwa pada pasien kanker, selain menjadikan mereka siap untuk membantu orang lain meningkatkan makna dan harapan dalam hidup, mereka juga mampu memberi harapan kepada orang lain. Juga, mereka menyimpulkan bahwa lebih dari $93 \%$ pasien kanker percaya bahwa spiritualitas membantu mereka untuk memperkuat harapan mereka.

Pada penelitian ini, hampir semua responden mengatakan ingin merasakan kedamaian, harapan yang sangat kuat untuk sembuh, dan selalu berpikiran positif akan adanya keajaiban tentang kesembuhan penyakitnya. Walaupun dari sudut pandang medis penyakit kanker stadium lanjut sulit disembuhkan dan mengarah pada kematian tapi kehidupan manusia adalah milik Sang Maha Kuasa, manusia tidak akan tahu apa yang akan terjadi dikemudian hari.

Keyakinan melalui spiritualitas/religius memberikan kekuatan dan motivasi dalam menjalani pengobatan hingga dinyatakan sembuh (Distinarista, 2018). Pengalaman penyesuaian diri tersebut menyebabkan penghayatan sebagai penderita kanker dan muncul harapan di masa depan dan pemaknaan terhadap sakit kanker (Dewi, Kahija, 2018; Rosyadi et al., 2019). 


\section{Dimensi Makna dan Tujuan}

Seperti kita ketahui penyakit fisik terutama kondisi terminal dapat bertindak sebagai pemicu dalam mempertimbangkan pertanyaan tentang hidup dan mati, apa arti hidup/alasan hidup ini sebenarnya, dan menemukan makna dalam penderitaannya saat ini. Untuk dapat memahami penyakitnya yang sedang diderita sangat sulit sekali bagi pasien terminal, kadang-kadang mereka perlu waktu lama untuk menerima kondisinya saat ini bahkan tidak menerima sampai akhir. Ditinjau dari karakteristik responden yang dominan adalah dewasa akhir, pada tahap ini bagi mereka yang spiritualnya kurang maka tujuan hidup juga kurang dan tidak mampu menerima kehidupan (Saarelainen, 2020).

Dari hasil wawancara dengan responden, sebagian dari mereka menerima keadaan sakit ini sebagai ujian/cobaan sehingga menerimanya dengan ikhlas, tapi sebagian kecil merasa tidak menerima kenapa penyakit tersebut menimpanya, terutama pada responden yang berada di usia dewasa pertengahan. Responden mengatakan masih banyak hal yang harus dilakukan terkait dengan perannya sebagai orang tua, yang harus membesarkan anakanaknya.

\section{Dimensi Resolusi/Kematian}

Pendapat ini didukung dalam jurnal Martins, Caldeira (2018) tentang peranan spiritual pada pasien terminal diuraikan bahwa kebutuhan spiritual yang terpenting adalah segera menyelesaikan masalah yang belum terselesaikan. Karena pada pasien terminal sangat penting untuk merasa siap sebelum meninggalkan dunia tanpa penyesalan karena masih ada masalah yang belum selesai. Mereka butuh rekonsiliasi, untuk dimaafkan dan memafkan agar menemukan kedamaian sebelum ajal menjemput.

Dalam kenyataannya pada saat pengambilan data dari karakteristik responden yang bekerja $(57,5 \%)$ dari total responden seluruhnya. Mereka mengatakan tidak terlalu memusingkan urusan pekerjaan karena walaupun banyak yang harus diselesaikan, karena hal yang terpenting adalah mengurus anak dan kondisinya saat ini membuat mereka sangat bergantung pada orang lain. Mereka akan serius lagi bekerja jika kondisinya sudah membaik. Dan dari karakteristik agama yang dominan yaitu agama Islam sangat mempengaruhi akan keputusan mereka akan kebutuhan resolusi/kematian. Mereka percaya bahwa hidup di dunia ini bukanlah tujuan akhir tapi masih ada kehidupan selanjutnya yang kekal yaitu kehidupan akherat. Jadi kematian adalah suatu proses yang harus dilalui menuju kehidupan yang abadi selama-lamanya. Tapi apabila perawat mengalami kesulitan dalam memberikan asuhan pada dimensi ini, perawat dapat melakukan kolaborasi dengan tokoh/pemuka agama, hal ini sesuai dengan pendapat Post et al., (2020) yang menyatakan tokoh/pemuka agama dapat dipanggil sewaktu-waktu jika diperlukan bagi pasien terminal.

Spiritualitas dianggap sebagai dimensi mendasar dari kesehatan pasien karena dapat meningkatkan perasaan tenang dan damai, terutama pada kondisi seseorang sedang mengalami krisis atau ketika didiagnosis penyakit yang mengancam jiwa atau penyakit keganasan (Martins, Caldeira, 2018; Martins et al., 2019). 


\section{Dimensi Apresiasi Keindahan}

Dimensi terakhir yang dibutuhkan responden adalah dimensi Apresiasi keindahan. Menikmati dan menghargai keindahan baik alam maupun seni dapat memberikan inspirasi dan rasa nyaman, menurunkan kecemasan dan musik juga dapat meningkatkan kreatifitas dan rasa damai dari dalam diri (Post et al., 2020).

Responden mengatakan hampir semua senang akan seni baik keindahan alam maupun musik. Kebutuhan ini dipilih oleh 15 responden terutama pasien dengan kelompok usia dewasa pertengahan (27-38 th). Mereka mengatakan tanpa suara musik terasa hambar, tapi sarana yang mendukung di RS, di beberappa ruangan masih belum terpenuhi untuk kebutuhan ini. Fasilitas televisi maupun radio khusus RS yang memutar lagu-lagu pun belum dimiliki. Banyak dari responden yang meminta supaya disediakan fasilitas hiburan agar tidak bosan/jenuh dalam menjalani perawatan.

Responden mengatakan sangat kurang menikmati keindahan alam karena alasan tidak sempat berdarmawisata dan penyakit yang dideritanya membuat mereka tidak memikirkan hal tersebut. Tapi ada juga kamar perawatan yang menghadap ke arah taman sehingga ada pula yang mengatakan cukup menikmati keindahan alam dari dalam kamar saja.

Contoh penerapan peran perawat sebagai pembaharu dalam dimensi apresiasi terhadap keindahan seperti membantu pasien dalam membudidayakan kepekaan estetika untuk keindahan disekitar ruangan pasien seperti memelihara kebersihan ruangan, menata ruangan sedemikian rupa dengan memperhatikan unsur seni seperti memajang lukisan atau disudut ruangan diberi pot-pot bunga.

\section{SIMPULAN}

Pasien kanker stadium lanjut yang dirawat di salah satu rumah sakit di Bandung membutuhkan pelayanan spiritual yang meliputi tujuh dimensi spiritual. Dimensi kebutuhan spiritual tertinggi adalah dimensi ketuhanan dan terendah dimensi apresiasi keindahan.

\section{SARAN}

Bagi perawat dalam perannya sebagai pemberi asuhan keperawatan, diharapkan mempunyai kemampuan memenuhi kebutuhan spiritual yang diperlukan oleh pasien kanker stadium lanjut. Salah satu peranan yang dapat dilaksanakan sebagai perawat pembaharu dari segi dimensi Apresiasi dan Keindahan adalah menata ruang rawat inap dengan memperhatikan unsur artistik. Untuk penelitian selanjutnya, penelitian ini dapat diterapkan untuk populasi yang lebih luas, misalnya pada pasien dengan kondisi terminal.

Temuan penelitian ini dapat membantu memprioritaskan perawatan pasien kanker dan juga cara perawatannya serta bagaimana cara berinteraksi dengan mereka. Selain itu tenaga kesehatan baik itu perawat dan tim pelayanan kesehatan lainnya diharapkan perlu memahami kebutuhan spiritual pasien dan merencanakan perawatan spiritual yang tepat sesuai kebutuhan pasien. 


\section{DAFTAR PUSTAKA}

Anita, A. (2016). Perawatan Paliatif dan Kualitas Hidup Penderita Kanker. Jurnal Kesehatan, VII(3), 508-513

Timmins, F., Murphy, M., Neill, F., Begley, T., \& S Arifin, R., \& Lestari, L. E. (2019). Penegakan dan Perlindungan Hak Asasi Manusia di Indonesia dalam Konteks Implementasi Sila Kemanusiaan yang Adil dan Beradab. Jurnal Komunikasi Hukum (JKH), 5(2), 12-25

Caldeira, S., Timmins, F., Carvalho, E. C., \& Vieira, M. (2017). Spiritual Well-Being and Spiritual Distress in Cancer Patients Undergoing Chemotherapy: Utilizing the SWBQ as Component of Holistic Nursing Diagnosis. Journal of Religion and Health, 56(4), 1489-1502

Dewi, P. F., \& Kahija, Y. F. (2018). Pengalaman Menderita Kanker Payudara Sebuah Interpretative Phenomenological Analysis. Empati, 7(1), 202-214

Distinarista, H. (2018). Spiritual Experience Among Cervical Cancer Survivors: A Phenomenology Study. Nurscope: Jurnal Penelitian dan Pemikiran Ilmiah Keperawatan, 4(1), 30. https://doi.org/10.30659/nurscope.4.1.30-40

Endiyono, E., \& Herdiana, W. (2016). Hubungan Dukungan Spiritual dan Dukungan Sosial dengan Kualitas Hidup Pasien Kanker Payudara di RSUD Prof. dr. Margono Soekarjo Purwokerto. Jurnal Ilmiah Ilmu-Ilmu Kesehatan, 14(2), 16-23. https://doi.org/10.1093/qjmed/hcy106/5003054

Komariah, M., \& Ibrahim, K. (2019). Training dan Coaching pada Pasien Kanker Payudara untuk Meningkatkan Ketaatan Melakukan Praktek Keagamaan. Media Karya Kesehatan, 2(2)

Martins, H., \& Caldeira, S. (2018). Spiritual Distress in Cancer Patients: a Synthesis of Qualitative Studies. Religions, 9(10), 285

Martins, H., Domingues, T., \& Caldeira, S. (2019). Spiritual Well-Being in Cancer Patients Undergoing Chemotherapy in an Outpatient Setting: A Cross-Sectional Study. Journal of Holistic Nursing, 0898010119858269

Mulyani, M., \& Ratnapuri, C. I. (2018). Nilai-Nilai Kepemimpinan Sunda: Definisi dan Model Konseptual. Jurnal Manajemen dan Bisnis Indonesia, 5(3), 327-345

Post, L., Ganzevoort, R. R., \& Verdonck, I. M. (2020). Transcending the Suffering in Cancer: Impact of a Spiritual Life Review Intervention on Spiritual Re-Evaluation, Spiritual Growth and Psycho-Spiritual Wellbeing. Religions, 11(3), 142

Puspita, R. R., \& Mahmudah, S. (2019). Hubungan Pemenuhan Kebutuhan Spiritual dengan Tingkat Kecemasan pada Pasien Kanker Di RSU Kabupaten Tangerang. Jurnal Keperawatan Dirgahayu (JKD), 1(2), 32-35

Rosyadi, I., Kusbaryanto, \& Yuniarti, F. A. (2019). Literatur Review Aspek Spiritualitas / Religiusitas Dan Perawatan Berbasis Spiritual / Religius Pada pasien kanker. Jurnal Kesehatan Karya Husada, 7(1), 108-127. http://jurnal.akeskhjogja.ac.id/index.php/jkkh/article/download/262/164

Saarelainen, S. M. (2020). Meeting the Spiritual Care Needs of Emerging Adults with Cancer. Religions, 11(1), 16 
Sajadi, M., Niazi, N., Khosravi, S., Yaghobi, A., Rezaei, M., \& Koenig, H. G. (2018). Effect of Spiritual Counseling on Spiritual Well-Being in Iranian Women with Cancer: A Randomized Clinical Trial. Complementary Therapies in Clinical Practice, 30, 79-84

Sastra, L., Büssing, A., Chen, C.-H., Yen, M., \& Lin, E. C.-L. (2020). Spiritual Needs and Influencing Factors of Indonesian Muslims with Cancer during Hospitalization. Journal of Transcultural Nursing, 1043659620908926

WHO. (2018). Evaluation of psychoactive substance use disorder treatment. Geneva: WHO

Widiasih, R., \& Nelson, K. (2018). Muslim Husbands' Roles in Women's Health and Cancer: The Perspectives of Muslim Women in Indonesia. Asian Pacific journal of cancer prevention: APJCP, 19(6), 1703 